\title{
Constituição Dos Saberes Da Formação Profissional No Curso De Licenciatura Em Matemática Para O Ensino De Estatística
}

\author{
Constitution Of The Knowledge Of The Professional Formation In The Course Of \\ Degree In Mathematics For The Teaching Of Statistics
}

\author{
Willian Damin * \\ Universidade Estadual do Norte do Paraná - (UENP) \\ Guataçara dos Santos Junior $^{* *}$ \\ Universidade Tecnológica Federal do Paraná (UTFPR) \\ Rudolph dos Santos Gomes Pereira*** \\ Universidade Estadual do Norte do Paraná - (UENP)
}

\begin{abstract}
Resumo
O objetivo deste presente artigo é apresentar as contribuições da oferta de um Projeto de Ensino de Estatística para a Educação Básica na formação inicial de professores de Matemática para a constituição dos saberes da formação profissional. O Projeto de Ensino de Estatística foi ofertado na modalidade presencial com carga horária total de 36 aulas de 50 minutos cada, utilizadas para leitura de textos na área da Educação Estatística, realizar tarefas estatísticas, construir/analisar materiais didáticos para o ensino de Estatística e Probabilidade, as competências estatísticas e o seu desenvolvimento na Educação Básica, realização de projetos de investigação estatística, confecção do memorial e narrativas de aprendizagem. Para a análise dos dados pautou-se na análise textual discursiva, que, permitiu categorizar os dados e interpretá-los de acordo com as falas dos licenciandos. Analisa-se a subcategoria Saberes provenientes da formação profissional e as suas unidades: saberes pedagógicos do conteúdo; saberes das ciências da educação/conhecimento de teorias e princípios educacionais e saberes do contexto educacional. As análises indicaram que os licenciandos demonstram conhecer formas de como abordar a Estatística e Probabilidade na Educação Básica e fazem referência ao contexto escolar. Definem e indicam aproximações das teorias pertencentes à Educação Estatística com o ensino e a aprendizagem.
\end{abstract}

Palavras-chave: Formação Inicial em Matemática, Educação Estatística, Projeto de Ensino de Estatística.

\begin{abstract}
The objective of this article is to present the contributions of the Project of Teaching Statistics for Basic Education in the initial formation teachers of Mathematics for the constitution of the vocational training

\footnotetext{
* Doutor em Ensino de Ciência e Tecnologia (UTFPR). Professor no curso de Licenciatura em Matemática (UENP), Cornélio Procópio, Paraná, Brasil. E-mail: wdamin@uenp.edu.br

** Doutor em Ciências Geodésicas (UFPR). Docente no Programa de Pós-Graduação em Ensino de Ciência e Tecnologia (UTFPR), Ponta Grossa, Paraná, Brasil. E-mail: guata@utfpr.edu.br

*** Doutor em Educação (UNESP). Docente no Programa de Pós-Graduação em Ensino (UENP), Cornélio Procópio, Paraná, Brasil. E-mail: rudolphsantos@uenp.edu.br
} 
knowledge. The Statistics Teaching Project was offered in the classroom mode with a total workload of 36 classes of 50 minutes each, used to read texts in the area of Statistical Education, to perform statistical tasks, to construct/analyze didactic subjects for the teaching of Statistics and Probability, the statistical competences and their development in Basic Education, the accomplishment of projects of statistical research, the making of the memorial and learning narratives. For the analysis of the data it was based on the discursive textual analysis, which allowed to categorize the data and to interpret them according to the statements of the licensees. The subcategory Knowledge from professional training and its units are analyzed: pedagogical knowledge of content; knowledge of educational sciences/knowledge of educational theories and principles. The analyzes indicated that the licenciandos demonstrate to know ways of approaching the Statistics and Probability in Basic Education and make reference to the school context. They define and indicate approximations of theories belonging to Statistical Education with teaching and learning.

Keywords: Initial Formation teachers of Mathematics, Statistical Education, Statistics Teaching Project.

\section{Introdução}

Apresenta-se neste artigo parte dos resultados encontrados na pesquisa de doutorado "A educação estatística e a formação inicial de Professores de matemática: contribuições de um Projeto para a constituição dos saberes docentes" (Damin, 2018). A posição adotada aqui é a constituição dos saberes profissionais no âmbito de um curso de Licenciatura em Matemática.

$\mathrm{Na}$ atual conjectura, em que no Brasil, as licenciaturas, incluindo o curso de Licenciatura em Matemática, estão passando por (re)estruturação e implementação de novos projetos pedagógicos, desencadeados pela publicação da Resolução ${ }^{\circ} 2$, de $1^{\circ}$ de julho de 2015 que define as Diretrizes Curriculares Nacionais para a formação inicial em nível superior, alguns pontos merecem atenção, tais como: a) a formação inicial do professor de Matemática para o ensino de Estatística e Probabilidade na Educação Básica; b) as práticas que os licenciandos irão participar, c) as ações específicas de um professor formador e; d) a contribuição dos currículos do Ensino Superior e da Educação Básica para prática docente.

Atualmente, a formação de grande parte dos professores está centrada no paradigma da racionalidade técnica (Cyrino, 2007) e a Resolução 02/2015 vem no sentido de tentar contribuir para a quebra dessa dicotomia, na qual em disciplinas específicas trabalha-se com os conteúdos de matemática acadêmica (ou científica) e nas disciplinas de cunho pedagógico aborda-se os conhecimentos que se julga necessário para a atuação em sala de aula.

Corroboramos com Cyrino (2007, p. 80), que, ao disponibilizarmos "contextos teóricos e conceituais imersos em diversas práticas, estimulando hábitos de conversar, investigar, questionar, refletir e relacionar teoria e prática num processo interativo" parece-nos lídimo, conceber o futuro professor como produtor de saberes profissionais. É nessa perspectiva que 
desenvolvemos um Projeto de Ensino de Estatística no curso de Licenciatura em Matemática para a Educação Básica, tendo em vista a articulação entre o conteúdo específico de Estatística e a sua abordagem pedagógica.

Por se tratar de um projeto de ensino que compõe uma pesquisa de doutorado acerca da Educação Estatística na formação inicial de professores, apresenta-se aqui apenas uma parte da análise dos dados, uma vez que a quantidade de informações produzidas no processo formativo pertence a um âmbito maior de investigação.

Portanto, o objetivo deste artigo é apresentar as contribuições da oferta de um Projeto de Ensino de Estatística na formação inicial de professores de Matemática para a constituição dos saberes da formação profissional para a prática pedagógica dos futuros docentes.

\section{Saberes Docentes E A Formação De Professores}

A literatura que discute a importância de conhecimentos teóricos e metodológicos e o desenvolvimento/manifestação dos saberes docentes de professores de Matemática pode ser considerada vasta, no entanto, pesquisas nessa área relacionadas com o Ensino de Estatística são em número reduzido. Inserida nessa temática de saberes docentes, entende-se que esta pesquisa apresenta novos elementos para essa discussão, uma vez que, investigamos as contribuições da oferta de um Projeto de Ensino de Estatística na formação inicial de professores de Matemática para o desenvolvimento das competências estatísticas.

$\mathrm{Na}$ década de 1980, iniciou-se nos Estados Unidos e Canadá um movimento reformista na formação inicial de professores da Educação Básica que tinha por objetivo a reivindicação de status profissional para os profissionais da Educação. Ancorados na premissa de que existe uma base de conhecimento ${ }^{1}$ para o ensino, muitos pesquisadores se mobilizaram a investigar e sistematizar esses saberes. Tentaram compreender a origem da atividade docente e, assim, convalidar um corpus de saberes mobilizados pelo professor com a intenção de melhorar a ação docente. Buscaram também, “iniciar um processo de profissionalização que favorecesse a legitimidade da profíssão e, dessa forma, transpusesse a concepção da docência ligada a um fazer vocacionado" (Almeida \& Biajone, 2007, p. 283).

Diante do movimento de profissionalização, a partir de 1990, América do Norte, Europa e América Latina aderiram a essas reformas educacionais. Segundo Borges e Tardif (2001), as

\footnotetext{
${ }^{1}$ Segundo Shulman (1986), em ensino, knowledge base (base de conhecimento) é o corpo de compreensões, conhecimentos, habilidades e disposições de que um professor necessita para atuar efetivamente numa dada situação de ensino.
} 
reformas em cursos no Brasil são provenientes desse movimento. Os autores citam como exemplo a Lei 9.394/96 de Diretrizes e Bases da Educação Nacional que permitiu o desenvolvimento de políticas públicas, como os Parâmetros Curriculares Nacionais (1998) e as Diretrizes Curriculares Nacionais para Formação de Professores da Educação Básica (2001). Destaca-se nesse último documento, a importância em estabelecer uma articulação entre as instituições de formação de professores e a Educação Básica.

Com base no novo modelo de formação profissional, no seio das reformas brasileiras, pesquisadores têm se dedicado à investigação do ensino, do trabalho e dos saberes dos docentes, mobilizados no decorrer de sua carreira. Vários são os autores (Shulman, 1986; Tardif, Lessard, Gauthier, 2001; Tardif, 2014) que têm investigado os aspectos constituintes da formação docente que contribuem para o desenvolvimento profissional do professor, de forma que este desenvolva competências e habilidades que possam auxiliá-lo em suas práticas pedagógicas.

Nesta pesquisa, aborda-se a dimensão dos saberes relacionados à Estatística e as suas abordagens tanto teóricas quanto metodológicas. Assim, acredita-se que o processo de formação docente, se alicerça sobre o saber, pois

[...] o saber é sempre o saber de alguém que trabalha alguma coisa no intuito de realizar um objetivo qualquer. Além disso, o saber não é uma coisa que flutua no espaço: o saber dos professores é o saber deles e está relacionado com a pessoa e a identidade deles, com a sua experiência de vida e com a sua história profissional, com as suas relações com os alunos em sala de aula e com os outros atores escolares na escola, etc (Tardif, 2014, p. 11).

A constituição dos saberes docentes se dá continuamente, desde a formação inicial, e se estende durante toda a trajetória de vida do professor. Estar em formação é construir maneiras de ser e estar na profissão, adquirir uma identidade profissional, que vem do querer do professor, contudo, é de responsabilidade das universidades que ofertam cursos de Licenciaturas e do compromisso das políticas públicas. Portanto, a formação inicial

deve promover a construção dos saberes docentes de maneira que estes relacionem os já validados cientificamente aos que estão em processo de construção por parte do professor, articulando o conhecimento adquirido na formação com a sua experiência de vida e profissional (Albuquerque; Gontijo, 2013, p. 79).

Percebe-se em Tardif (2014) uma perspectiva de formação docente que visa articular diferentes saberes, como os saberes da formação profissional que incluem os saberes das Ciências da Educação e da ideologia pedagógica; os saberes disciplinares; os saberes curriculares e os saberes experienciais.

Os saberes da formação profissional são a composição de conhecimentos baseados nas 
ciências e no entendimento cultural e são veiculados pelas instituições de formação de professores. Assim, "esses conhecimentos se transformam em saberes destinados à formação científica ou erudita dos professores, e, caso sejam incorporados à prática docente, esta pode transformar-se em prática científica, em tecnologia da aprendizagem" (Tardif, 2014, p. 37).

A prática docente é também, uma atividade que mobiliza diversos saberes, chamados de saberes pedagógicos que se relacionam aos métodos e técnicas de ensino (saber-fazer), que são transmitidos aos professores continuamente em sua formação inicial ou continuada.

Os saberes pedagógicos apresentam-se como doutrinas ou concepções provenientes de reflexões sobre a prática educativa no sentido amplo do termo, reflexões racionais e normativas que conduzem a sistemas mais ou menos coerentes de representação e de orientação da atividade educativa (Tardif, 2014, p. 37).

Portanto, o professor precisa construir o saber-fazer em relação aos saberes da educação científica e a atividade de formação profissional dos professores deve acontecer de forma articulada entre os diversos saberes, dentre eles, os que destacamos neste artigo: Saberes provenientes da formação profissional e as suas unidades: saberes pedagógicos do conteúdo; saberes das ciências da educação/conhecimento de teorias e princípios educacionais e saberes do contexto educacional.

\section{O Campo Da Educação Estatística}

Alguns fatos ligados a Educação Estatística merecem destaque, pois, colaboraram para uma maior visibilidade dessa área por meio de publicações em edições especiais, eventos específicos ou da área da Educação Matemática, consolidando a Educação Estatística como campo de pesquisa. Apresenta-se as contribuições em âmbito internacional e nacional.

Destaca-se o Statistics Education Research Journal (SERJ), um dos meios de veiculação de grande referência de pesquisas em Educação Estatística no mundo, o qual lançou em 2014 uma edição especial com a temática "A Global View of Statistics Education Research". O objetivo dessa edição era estimular pesquisadores de países com pouca representatividade nas edições anteriores dessa revista a apresentarem seus trabalhos. A edição contou com 8 trabalhos de brasileiros, de um total de 16 publicados.

O International Conference on Teaching Statistics (ICOTS), que é organizado pelo International Association for Statistics Education (IASE) quadrienalmente, desde 1982, e tem como objetivo implementar e desenvolver mundialmente a Educação Estatística em todos os níveis de ensino. 
Ainda em âmbito internacional, o Guidelines for Assessment and Instruction in Statistics Education (GAISE) Report: a Pré-K-12 Curriculum Framework é um documento aprovado pela American Statistical Association (ASA), em 2005, que ratifica a importância do Tratamento da Informação na formação do aluno e apresenta a Literacia Estatística ${ }^{2}$ como objetivo principal da Educação Estatística, tendo em vista que a vida cotidiana é orientada por números e informações que necessitam de um raciocínio estatístico adequado para tratar de forma inteligente questões relacionadas à cidadania, emprego e família, de forma a buscar uma vida com mais qualidade (Asa, 2005). O documento também salienta a necessidade de se desenvolver a análise de dados por meio da coleta, organização e apresentação de dados, ao mesmo tempo em que enfatiza o desenvolvimento e a avaliação de inferências e predições com a seleção e utilização de métodos e ferramentas adequados.

No Brasil, no ano de 2000 foi criado o Grupo de Trabalho (GT-12), composto por pesquisadores que atuam na área de Educação Estatística, da Sociedade Brasileira de Educação Matemática (SBEM), que tem como objetivo a compreensão do ensino e aprendizagem de Estatística, envolvendo aspectos cognitivos, afetivos, epistemológicos e o desenvolvimento de materiais de apoio para o desenvolvimento do letramento estatístico.

O Encontro Nacional de Educação Matemática (ENEM), o Congresso Internacional de Ensino da Matemática (CIEM) e a Conferência Interamericana de Educação Matemática (CIAEM) são alguns dos eventos que ocorreram em âmbito nacional e internacional e que também publicaram artigos na área da Educação Estatística. No entanto, o primeiro evento de maior visibilidade no país, foi a I Conferência Internacional de Educação Estatística "Experiências e Expectativas do Ensino de Estatística - Desafios para o século XXI", que ocorreu em 1999, na Universidade Federal de Santa Catarina (UFSC), em Florianópolis.

O Boletim de Educação Matemática (BOLEMA), um dos periódicos mais importantes do país na área de Educação Matemática, publicou em 2011, uma edição temática de Educação Estatística em dois volumes, totalizando de 26 artigos. Em 2016 a Revista Vidya lançou uma edição especial sobre o Ensino de Probabilidade e Estatística e, a Educação Matemática Pesquisa publicou pesquisas em Educação Estatística. A Revista de Ensino de Ciências e Matemática (RENCIMA) publicou uma edição temática em 2018 e, em seu editorial ressalta o crescimento significativo da produção científica no campo da Educação Estatística, frisando a importância do letramento estatístico.

Algumas mudanças ocorridas no Brasil no final da década de 1990, só foram possíveis

\footnotetext{
${ }^{2}$ Esse termo será discutido mais adiante.
} 
devido a promulgação dos Parâmetros Curriculares Nacionais (PCN) em 1997, no qual propõem o ensino de Estatística por meio do bloco Tratamento da Informação que incluem os conteúdos de Estatística, Probabilidade e Combinatória. Esse documento destaca que a finalidade da Estatística é proporcionar ao aluno a capacidade de construir procedimentos para coletar, organizar, comunicar dados, fazendo o uso de tabelas, gráficos e representações que aparecem com frequência em seu cotidiano. Além disso, com o objetivo de fornecer novos elementos para interpretar dados estatísticos, o documento destacou a importância de desenvolver a capacidade de calcular algumas das medidas estatísticas como média, mediana e moda (Brasil, 1998).

Lopes (2003) considera que a tríade Estatística, Matemática e Educação mantêm uma relação dependente, dando origem assim à Educação Estatística que centraliza seus objetivos no desenvolvimento do pensamento probabilístico e estatístico, e se preocupa com os assuntos relacionados ao ensino e aprendizagem de conceitos nessa área.

A Educação Estatística e a Educação Matemática em muitos momentos compartilham de teorias de aprendizagem ou aspectos metodológicos, no entanto, Estatística e Matemática se diferenciam na medida em que apresentam aspectos teóricos distintos. A Estatística busca produzir um pensamento e raciocínio crítico, com tomada de decisões com base em situações que envolvem, por exemplo, erros, incertezas, aleatoriedades, aproximação e estimação. A Educação Estatística se caracteriza como uma área de pesquisa cujo interesse está voltado para o ensino e a aprendizagem de conceitos estatísticos e probabilísticos.

No campo da Educação Estatística destaca-se o desenvolvimento das competências estatísticas, a saber, o letramento, o pensamento e o raciocínio estatístico. Dizemos desenvolvimento, pois, entendemos que elas não podem ser ensinadas, contudo, é possível oferecer aspectos que possibilitam o desenvolvimento dessas competências.

O letramento estatístico consiste na habilidade de comunicação estatística e envolve “[...] ler, escrever, demonstrar e trocar informações, interpretar gráficos e tabelas e entender as informações estatísticas dadas nos jornais e outras mídias, sendo capaz de se pensar criticamente sobre elas" (Campos, Wodewotzki \& Jacobini, 2011, p. 44).

$\mathrm{O}$ raciocínio estatístico refere-se à habilidade de trabalhar com ferramentas e com conceitos estatísticos, o que envolve "fazer interpretações sobre dados, representações gráficas, construção de tabelas, etc [...]”(Campos, Wodewotzki \& Jacobini, 2011, p. 119).

O pensamento estatístico é definido como "[...] a capacidade de utilizar, de forma adequada, as ferramentas estatísticas na solução de problemas, de entender a essência dos dados 
e de fazer inferências" (Cazorla, 2002, p. 19).

$\mathrm{Na}$ tentativa de elucidar as três competências estatísticas, elaborou-se o Quadro 1, relacionando palavras, o que é necessário para alcançá-las e o que os professores podem propor para que elas sejam desenvolvidas.

\begin{tabular}{|c|c|c|c|}
\hline & $\begin{array}{c}\text { LETRAMENTO } \\
\text { ESTATÍSTICO }\end{array}$ & $\begin{array}{l}\text { RACIOCÍNIO } \\
\text { ESTATÍSTICO }\end{array}$ & $\begin{array}{l}\text { PENSAMENTO } \\
\text { ESTATÍSTICO }\end{array}$ \\
\hline $\begin{array}{l}\text { Palavras } \\
\text { relacionadas }\end{array}$ & $\begin{array}{lr}\text { Identificar. } & \text { Descrever. } \\
\text { Parafrasear. } & \text { Traduzir. } \\
\text { Interpretar. Ler } & \\
\end{array}$ & $\begin{array}{l}\text { Por que? Como? Explicar um } \\
\text { processo }\end{array}$ & $\begin{array}{l}\text { Aplicar. Criticar. Avaliar. } \\
\text { Generalizar. Planejar }\end{array}$ \\
\hline É necessário & $\begin{array}{l}\text { O conhecimento de conceitos } \\
\text { e procedimentos básicos de } \\
\text { Estatística e Probabilidade }\end{array}$ & $\begin{array}{c}\text { Decidir, baseado na observação } \\
\text { de dados, qual a melhor } \\
\text { estratégia a seguir em uma } \\
\text { determinada situação de } \\
\text { incerteza }\end{array}$ & $\begin{array}{c}\text { Reconhecimento da } \\
\text { variação presente em todo } \\
\text { o processo }\end{array}$ \\
\hline $\begin{array}{c}\text { Os } \\
\text { professores } \\
\text { devem }\end{array}$ & $\begin{array}{l}\text { Propor questões ou tarefas aos } \\
\text { alunos que envolvam } \\
\text { identificação de conceitos } \\
\text { estatísticos, descrição de } \\
\text { gráficos e interpretação de } \\
\text { resultados obtidos }\end{array}$ & $\begin{array}{c}\text { Propor aos alunos que } \\
\text { expliquem e justifiquem um } \\
\text { resultado ou a escolha de uma } \\
\text { representação }\end{array}$ & $\begin{array}{c}\text { Propor aos alunos que } \\
\text { critiquem as conclusões } \\
\text { de um estudo e } \\
\text { generalizem os resultados } \\
\text { obtidos em uma } \\
\text { investigação }\end{array}$ \\
\hline
\end{tabular}

Fonte: Autores

Para que ocorra uma melhora no desenvolvimento das competências estatísticas dos estudantes, faz-se se necessário que eles aprendam a utilizar a Estatística em sua vida diária, seja como trabalhadores, consumidores ou cidadãos. Utilizar o contexto em que o aluno vive, se tornou um dos pilares da Educação Estatística, visto que, evidenciar e relacionar a Estatística com assuntos que fazem parte da vida dos estudantes pode melhorar a construção de uma fundamentação estatística que será utilizada por eles para comprovar resultados obtidos por uma pesquisa, proporcionando significado ao que se aprende (Campos, 2007).

Desse modo, no desenvolvimento de tarefas em uma situação-problema real pode surgir a necessidade de utilizar a Estatística para analisar, interpretar, representar e/ou prever resultados relacionados ao problema. Diferentes conhecimentos que não pertencem à Estatística ou à Matemática podem ser necessários. É aqui que sinaliza-se o porquê das tarefas de Estatística que compõem um Projeto de Ensino de Estatística proporcionarem a manifestação e o desenvolvimento da base de conhecimentos da docência. São as particularidades das tarefas de Estatística, descritas anteriormente, que podem contribuir para o desenvolvimento profissional do futuro professor.

Portanto, existe uma necessidade de transformação nas práticas formativas e superação do modelo aplicacionista do conhecimento, valorizando os saberes dos professores, tais como estes os mobilizam e utilizam em diversos contextos, que visem habituar os licenciandos à 
prática profissional (Almeida \& Biajone, 2007).

\section{Aspectos Metodológicos}

Esta pesquisa envolve uma metodologia qualitativa no que se refere à abordagem do problema, uma vez que o pesquisador buscou coletar e analisar dados que permitiram investigar as contribuições da oferta de um Projeto de Ensino de Estatística na formação inicial de professores de Matemática para o desenvolvimento das competências estatísticas e para a prática docente.

O Projeto de Ensino de Estatística (PEE) foi ofertado na modalidade presencial, dentro da disciplina de Estatística, em horário de aula e aos sábados, para a contribuição da formação inicial de professores de Matemática. A carga horária total do PEE para a Educação Básica foi de 36 aulas de 50 minutos cada, utilizadas para leitura de textos na área da Educação Estatística, realizar tarefas estatísticas ${ }^{3}$, construir/analisar materias didáticos para o ensino de Estatística e Probabilidade, as competências estatísticas e o seu desenvolvimento na Educação Básica, realização de projetos de investigação estatística, confecção do memorial e narrativas de aprendizagem.

O memorial reflexivo consistiu em uma produção escrita e possibilitou aos participantes da pesquisa que registrassem as suas vivências no decorrer da aplicação das atividades do projeto, que podem ser considerados os saberes práticos como definido por Tardif (2014), entregue em três momentos distintos do curso. Já as narrativas de aprendizagem que também consistiam em uma produção escrita, eram entregues ao término de cada aula, de forma a explicitar os saberes daquele momento.

Para a organização dos dados, os licenciandos e os instrumentos de coleta de dados foram decodificados com os seguintes indicadores simbólicos dispostos no Quadro 2.

Quadro 2 - Decodificação

\begin{tabular}{|c|c|}
\hline DESCRIÇÃO & INDICADORES SIMBÓLICOS \\
\hline Licenciandos & $\mathrm{L} 1, \mathrm{~L} 2, \ldots, \mathrm{L} 11$ \\
\hline Memoriais reflexivos & $\mathrm{M} 1, \mathrm{M} 2$ e M3 \\
\hline Narrativas de aprendizagem & $\mathrm{N} 1, \mathrm{~N} 2, \ldots, \mathrm{N} 17$ \\
\hline Tarefas & $\mathrm{T} 1, \mathrm{~T} 2, \ldots, \mathrm{T} 8$ \\
\hline
\end{tabular}

Fonte: Autores

\footnotetext{
${ }^{3}$ As tarefas de Estatística envolviam conceitos de Estatística Básica e Probabilidade, como medidas de tendência central e eventos e, a discussão da possibilidade e modificações dessas atividades para a Educação Básica, tendo em vista a prática pedagógica.
} 
Para a análise dos dados coletados em sala de aula foi utilizados a Análise Textual discursiva de Moraes e Galiazzi (2007). As frases apresentadas pelos licenciandos, em diferentes momentos, foram representadas simbolicamente após cada excerto. Como forma de sintetizar o volume de dados em cada categoria de análise, com base na regra da representatividade da análise textual discursiva, optou-se pela escolha de uma frase de um licenciando que fosse representativa em relação a outras informando os respectivos indicadores simbólicos.

O projeto de pesquisa que norteou esta tese foi submetido à apreciação do Comitê de Ética em pesquisa, sob registro CAAE: 58954216.7.0000.0108, com parecer número: 2.104.853.

\section{Resultados E Discussões}

Constituem a subcategoria "Saberes da formação profissional" o conjunto de saberes baseados nas ciências e na erudição que foram desenvolvidos e/ou manifestados pelos licenciandos durante o processo de formação inicial. Correspondem aqui, às maneiras e formas de abordar a Estatística e Probabilidade, de modo a torná-las mais compreensíveis aos alunos da Educação Básica.

Os licenciandos demonstram conhecer formas de como abordar a Estatística e Probabilidade na Educação Básica e fazem referência ao contexto escolar. Definem e indicam aproximações das teorias pertencentes à Educação Estatística com o ensino e a aprendizagem. Evidenciam ainda a compreensão sobre o uso do contexto pertencente a outras disciplinas que podem auxiliar no processo de ensino e de aprendizagem e a realidade dos alunos.

$\mathrm{Na}$ unidade "Saberes pedagógicos do conteúdo" os licenciandos apresentam um repertório de estratégias para ensinar o conteúdo específico, de modo a torná-lo compreensível ao aluno. Indicam ações necessárias para um ensino contextualizado da Estatística e que façam sentido para o aluno, nas quais ele participa do processo de construção do seu conhecimento. Com alguns excertos é possível perceber a manifestação de uma ação docente voltada para a melhoria da educação, motivando a aprendizagem pela compreensão da aplicabilidade do conteúdo em seu contexto.

Algumas ações são sugeridas como: trabalhar com dados reais; relacionar os dados ao contexto em que estão inseridos; orientar os alunos para que interpretem os resultados; permitir que os estudantes trabalhem em grupo para que assim haja um debate entre eles; promover algumas conclusões (L11N5). 
[...] ao realizar uma aula de Estatística ou de qualquer outro conteúdo matemático é preciso termos em mente que devemos conduzir o aluno a pensar criticamente, levar situações em que o mesmo tenha contato em seu dia a dia, utilizar diferentes metodologias para tentar alcançar a todos da turma (L4M3).

Tendo em vista a necessidade de que um professor que não saiba apenas conceitos, mas também, que os compreenda à luz de um método investigativo (Mizukami, 2004), o PEE proporcionou aos licenciandos encontrarem diferentes formas de ensinar, dentre elas a contextualização, tornando o conteúdo compreensível para seus alunos, adaptando a situações reais.

Com base nos registros L11N5 e L4M3, os licenciandos desenvolveram a compreensão dos objetivos de uma aula de Estatística, ampliando seus saberes pedagógicos do conteúdo, que se configuram como as ações em sala de aula e a abordagem de um tema, na intenção de contribuir com a aprendizagem do aluno. Compreendem que o trabalho com dados reais é mais significativo, de forma que pode fomentar a um pensamento crítico, conforme esperado com o ensino da Estatística.

Os licenciandos entendem a importância dos saberes docentes para a atuação profissional e a necessidade de novos conhecimentos conforme excerto de A2M1 ao relatar o que espera ao fim de sua formação inicial “[...] ser professores que dominam e saibam como conduzir uma aula de estatística que não seja apenas voltada para o ensino de formulas/equações, mas sim para a formação de futuros cidadãos que viveram em sociedade". Identifica-se uma preocupação com a aprendizagem dos alunos na intenção de proporcionar habilidades essenciais para a participação na sociedade, como a análise crítica e a argumentação, fugindo do ensino mecânico e de técnicas, como propõe Lopes (2008).

De acordo com Lopes (2013, p. 905) "para ensinar estatística, não é suficiente entender a teoria matemática e os procedimentos estatísticos; é preciso fornecer ilustrações reais aos estudantes e saber como usá-las para envolver os alunos no desenvolvimento de seu juízo crítico”. É possível identificar na afirmação de Lopes (2013) a necessidade dos saberes pedagógicos do conteúdo de Estatística e as formas de transformar conteúdo estatístico em conteúdo de ensino, como pode ser visto nos excetos L4N10 e L3N10.

Como forma de ensinar Estatística podemos utilizar as etapas de um ciclo investigativo: problema (compreensão do problema), planejamento (estratégias de como resolver determinado problema), dados (coleta dos dados), análise (analises exploratórias, análises planejadas, análises emergentes e hipóteses) e conclusão (considerações sobre o problema). Dessa forma, pode-se desenvolver nos alunos o pensamento estatístico, letramento estatístico e raciocínio estatístico, pois o aluno irá formular o problema interpretar os dados e utilizar de recursos estatísticos para a resolução e compreensão do problema (L4N10). 
Em sala de aula é possivel desenvolver competências, envolvidas com os objetivos ou problema proposto no início da investigação. Desse modo, a investigação propõe ao aluno pensar, analisar, questionar e refletir sobre o tema escolhido. Com isso, é de suma importância propor investigações em sala de aula, para que o aluno possa compreender algumas situações em sua volta e desenvolve-las em seu cotidiano (L3N10).

Os excertos indicam a percepção dos licenciandos sobre o ciclo investigativo e a sua potencialidade para trabalhar com os diversos conteúdos de estatística, reconhecendo a necessidade do desenvolvimento das competências estatísticas. Ao compreenderem um ciclo investigativo, a relação dos licenciandos com os saberes não se reduz a uma função de transmissão dos conhecimentos já constituídos, pois, a capacidade de incentivá-los a pensar sobre cada fase da investigação e considerar a forma como as fases estão interligadas são exemplos de conhecimentos estatísticos necessários para o ensino (Burgess, 2007), entendidos como saber da formação profissional, como apresentado em Tardif (2014).

Conforme o excerto de L4N1, o desenvolvimento do PEE possibilitou a articulação entre Estatística e Probabilidade e as tendências metodológicas "Para trabalhar com esses conteúdos o professor pode utilizar recursos tecnológicos [...]”, tendo em vista o disposto em Paraná (2008, p. 65), ao propor a abordagem de conteúdos por meio das mídias tecnológicas, "pois dinamizam os conteúdos curriculares e potencializam o processo pedagógico". A mobilização de conhecimentos já adquiridos em sua formação anterior "[...] e também materiais manipuláveis, como o da raquete, para adquirir dados amostrais (L4N1)” é evidenciado, pois, mostra que o licenciando articula seu repertório de saberes para uma prática formativa.

O ensino de Estatística e Probabilidade deve proporcionar ao aluno situações que the permitam a superação do determinismo em favor da aleatoriedade, desta forma, o desenvolvimento do pensamento estatístico e probabilístico, pode efetivar as potencialidades formativas da disciplina de Matemática (Lopes, 2008).

O registro L3T4 "um exemplo que pode servir de sugestão é o da moeda, onde os alunos jogam as moedas e calculam a probabilidade de sair cara ou coroa", apesar de não apresentar um alto grau de complexidade, mostra um cuidado de articulação, feito pelo licenciando, entre a realidade e o conteúdo de probabilidade. Entende-se que a partir dessa situação inicial é possível que o professor consiga oferecer continuidade no conteúdo de maneira mais formal, com profundidade e assim, abordar a aleatoriedade, considerada o núcleo do conhecimento probabilístico (Azcárate, Cardeñoso \& Pórlan, 1998), que envolve a incerteza, uma condição para garantir a equidade e justiça. No entanto, "é um dos principais pontos em que os sujeitos 
demonstram incompreensão, embora essa fragilidade diminua à medida que os futuros professores lidam com a Probabilidade em disciplinas específicas" (Cavalcante, Andrade \& Régnier, 2016, p. 453). Sinaliza-se aqui, a necessidade da articulação dos diferentes saberes, como indica Tardif (2014), sobretudo os saberes disciplinares e os saberes pedagógicos do conteúdo, para a efetivação do ensino. É nesse sentido que a oferta de uma formação que possibilita ao licenciando vivenciar atividades práticas e contextualizadas contribui para o ensino, o que foi registrado pelo licenciando no excerto a seguir:

No ensino de Estatística e Probabilidade se faz necessário, uma prática pedagógica na qual sejam propostas situações em que os estudantes realizem atividades que permitam que os mesmos possam observer e construir eventos possiveis, por meio da experimentação concreta, da coleta e organização de dados (A6N2).

Conforme Albuquerque e Gontijo (2013) a formação deve oportunizar a aquisição de novos conhecimentos, a significação e ressignificação desses conhecimentos continuamente, e estendida durante toda a sua trajetória profissional, pois os saberes da formação profissional se originam das diversas fontes (Tardif, 2014) e devem ser mobilizados no decorrer do desenvolvimento profissional do licenciando, ao almejar uma prática docente pautada na associação entre os diferentes saberes. Portanto, os conhecimentos, os saberes, as formas de ser e de fazer são oriundos das experiências vivenciadas, e assim, dá-se sentido as relações estabelecidas no exercício da profissão, como apresentado no registro:

O desenvolvimento desta atividade ajuda o aluno a desenvolver a concepção de probabilidade por meio da tentativa e erro. É uma boa atividade para introduzir o conteúdo e assim os alunos conseguirão raciocinar melhor e entender o conceito (L8T4), (L3T4), (L6N7).

Os licenciandos se referem à tarefa "Simulação de um dado equilibrado" como uma estratégia para o ensino introdutório de Probabilidade e citam o uso de jogos como auxílio no desenvolvimento de atividades.

A utilização de jogos ajuda muito no auxilio desses conteúdos para introduzir, por ser uma maneira diferente da tradicional (L8N7), (L10N2), (L1M1), (L2M1), (L3M1).

Eles citam o jogo como uma estratégia pedagógica que pode auxiliar o processo de ensino e aprendizagem de Estatística e Probabilidade na perspectiva de contribuir com o desenvolvimento de competências estatísticas, como as atitudes, a comunicação matemática e a criticidade do aluno, ao enfrentar desafios.

Percebe-se que os licenciandos entendem a necessidade de uma formação voltada para a prática pedagógica e fazem menção aos conteúdos que devem ser ensinados, articulando Estatística e Probabilidade. Embora o PEE tenha abordado conteúdos de Probabilidade, 
acredita-se que uma atenção também deva ser dispensada em outras disciplinas da formação inicial, para fornecer conhecimento conceitual e pedagógico sobre esse tema, tendo em vista que para a consolidação de uma ação docente mais efetiva, requer-se ciclos contínuos de formação.

Na unidade "Saberes das ciências da educação/Conhecimento de Teorias e princípios educacionais" apresenta-se os registros dos licenciandos que se referem às teorias do campo da Educação Estatística que contribuem para a compreensão de questões relativas ao ensino e aprendizagem.

Costa e Nacarato (2011) consideram um desafio ao professor de Matemática trabalhar em uma perspectiva mais crítica, tendo em vista que a sua formação, no que se refere ao conhecimento matemático, é pautada na ideologia da certeza. Entretanto, o PEE ao possibilitar preparar os licenciandos para tornarem-se profissionais, permitiu que eles pensassem de forma não determinística "a literacia estatística também inclui um entendimento de probabilidade como medida de incerteza, L5N5". Que observassem a importância de um contexto para o problema "[...] a aprendizagem da estocástica só complementará a formação dos alunos se for significativa, com situações contextualizadas, (L5N2)”, a estrutura estatística e matemática presente "[...] comunicar as discussões que envolvem os resultados de investigações estatísticas utilizando-se da matemática e da terminologia estatística” (L4M2). E entendessem a existência de fenômenos aleatórios "o pensamento estatístico inclui: [...] consideração da variação [...]” (L5N5) e as competências estatísticas envolvidas "o aluno ao desenvolver essas três competências estatísticas será capaz de analisar e interpretar dados criticamente [...]" (L4M2).

Os licenciados consideram importante ensinar aos alunos da Escola Básica o caráter conceitual da estatística, a forma de distinguir a veracidade e os graus de incerteza. Para isso, relacionam as competências estatísticas com o ensino, destacando a relevância da interpretação com criticidade e a participação do aluno na sociedade.

O aluno ao desenvolver essas três competências estatísticas será capaz de analisar e interpretar dados criticamente, verificando a veracidade das informações, estando apto para viver em sociedade e analisar dados de diferentes perspectivas, ou seja, analisar uma tabela, um gráfico, organizar dados, de modo que isso auxilie e não seja manipulado por dados incorretos (L4M2).

Os registros apontam qual a definição de letramento estatístico na concepção dos licenciandos, advinda das tarefas realizadas e das discussões dos textos escolhidos para compor o PEE.

O letramento estatístico se refere à capacidade de comunicação estatística, o que envolve: ler, escrever, demonstrar e trocar informações, interpretar gráficos e tabelas e entender as 
informações estatísticas dadas nos jornais e outras mídias, sendo capaz de se pensar criticamente sobre elas (L4M2), (L3M2).

Eles também indicam as habilidades necessárias para que uma pessoa seja considerada letrada estatisticamente, remetendo às discussões e resultados que uma investigação estatística pode proporcionar. Como os licenciandos participaram de uma investigação, articulam os seus objetivos com o letramento estatístico.

Para se considerar que uma pessoa seja letrada estatisticamente, ela deverá ser capaz de argumentar com base em informações e observações, além de comunicar as discussões que envolvem os resultados de investigações estatísticas utilizando-se da matemática e da terminologia estatística (L4N2).

Apresentam a definição de pensamento estatístico e salientam que na construção de tabelas essa competência foi desenvolvida, isto é, referem-se ao raciocínio com modelos estatísticos.

Já em relação a uma outra competência que é o pensamento estatístico, podemos dizer que é a capacidade de utilizar de forma adequada as ferramentas estatisticas e de entender os dados. Ocorreu a construção de várias tabelas distintas, isso fez com que essa competência acontecesse (L3N12).

O pensamento estatístico inclui: a) reconhecimento da necessidade dos dados; b) transnumeração, que é a mudança de um registro para o outro; c) consideração da variação; d) raciocínio com modelos estatísticos; e) integração contextual da estatística (L5N5).

Os cinco tipos de pensamentos descritos pelo registro L5N5 é baseado em Campos et al. (2011), indicando que a inserção de textos no PEE contribuiu para a interação dos licenciandos nas discussões realizadas, para a apropriação de conhecimentos teóricos sobre a Estatística e para o entendimento das competências estatísticas.

Os registros L3N12 e L6N5 mostram que os licenciandos entendem que a interpretação dos dados está relacionada com o raciocínio estatístico. $\mathrm{Na}$ investigação estatística desenvolvida com eles, foi pedido que analisassem e representassem os dados coletados com o questionário. Dentre as formas de representação, indicam as tabelas e alguns conteúdos que são necessários para a sua construção.

[...] a última competência é o raciocínio estatístico que envolve fazer a interpretação dos dados [...]. Essa competência foi desenvolvida nessa atividade, pois ocorreu a interpretação dos dados de um questionário para a construção de tabelas, utilizando alguns conceitos como frequência, intervalos de classe, entre outros (L3N12).

Raciocinar com ideias estatísticas envolve a aleatoriedade e a incerteza como aponta o registro L6N5 “o raciocínio estatístico consiste na maneira pela qual as pessoas raciocinam com ideias estatísticas e dá sentido a informação estatística. É usar as ideias de aleatoriedade 
para fazer julgamentos". Dessa forma, "a idéia de incerteza na Estatística advém, principalmente, da sua forte ligação com o contexto, pois na Estatística é o contexto, o entorno, que determina o sentido de um resultado" (Pamplona \& Carvalho, 2009, p. 51).

Assim como o raciocínio sobre a incerteza foi destacado, o excerto de L6N5 apresenta outros tipos de raciocínio necessários para o desenvolvimento do raciocínio estatístico.

[...] atividades de familiriarização com a estatística; raciocínio sobre a representação dos dados; raciocínio sobre as medidas estatísticas; raciocínio sobre a incerteza; raciocínio sobre amostragem e raciocínio sobre associação (L6N5).

Ao considerar a amplitude de conhecimentos que o professor de Matemática precisa ter para possibilitar que seus alunos desenvolvam o letramento, o pensamento e o raciocínio estatístico, o PEE proporcionou a constituição de um repertório de saberes para atuar profissionalmente, dentre eles os contidos pelas teorias da educação e Educação Estatística. Esses saberes são relevantes para a formação do licenciando, permitindo que ampliem seus saberes, de modo que possam olhar por diferentes perspectivas e compreender os diferentes contextos que vivenciam, pensando em uma prática contextualizada, repleta de técnicas e, metodologias.

$\mathrm{Na}$ unidade "Saberes do contexto educacional" apresenta-se a concepção dos licenciandos sobre o contexto escolar e as suas preocupações com a atuação em sala de aula.

No excerto L9N1 "Se eu já tivesse que lecionar na educação básica teria uma certa dificuldade" o licenciando reconhece a dificuldade em exercer a profissão, sobretudo no que diz respeito aos conteúdos de Estatística e Probabilidade. Esse excerto mostra a barreira existente entre as disciplinas específicas e as de cunho pedagógico.

[...] os conteúdos estatística e probabilidade são normalmente discutidos, nos cursos pesquisados, em uma disciplina apenas, localizada na segunda metade do curso e desarticulada de outras, portanto, privando o licenciando de questionar as formas de abordagem destes conteúdos na educação básica, bem como de discutir questões curriculares [...] (Silva, 2011, p. 761).

Os licenciandos relatam a abordagem do conteúdo de forma tradicional, feita pelos professores do curso, insuficiente para provocar uma mudança no modelo vivenciado pelos licenciandos ao cursarem as disciplinas específicas que tratam Estatística e Probabilidade.

Contudo, ainda existem dúvidas, pois, são muitas as maneiras de se desenvolver os conteúdos estatísticos em sala de aula. A probabilidade de conhecê-los de maneiras distintas da tradicional ainda é pequena, pois são poucos os professores que a abordam em sala de aula na formação (L2M1), (L3M1). 
Como consequência dessa dicotomia, existe um reflexo na Educação Básica, e esses conteúdos são ensinados de forma mecânica e sem contextualização, muitas vezes baseados apenas nos livros didáticos (Costa, 2007).

Os estudantes devem realizar atividades envolvidas em seu contexto. A aprendizagem da estocástica só complementará a formação dos alunos se for significativa, com situações contextualizadas (L5N2).

Identificar a relação dos conteúdos estatísticos e probabilísticos com o mundo real e articular o que se aprende no curso de Licenciatura em Matemática com o currículo a ser ensinado foram apropriações pertencentes ao PEE, atendendo ao disposto em Brasil (2001) ao indicar a aproximação entre a formação de professores com o contexto da Educação Básica.

Entretanto, entende-se que com o exercício docente, outras dúvidas poderão surgir, pois

o professor, na sua atividade profissional diária, defronta-se com múltiplas situações para as quais não encontra respostas preestabelecidas. Para fazer-lhes face, tem de pôr em movimento um conhecimento que envolve elementos com origens diversas incluindo acadêmicas e experiências -, bem como aspectos de foro pessoal e contextual (Lopes, 2008, p. 64).

O desenvolvimento do PEE proporcionou aos licenciandos elaborar e realizar tarefas de Estatística e Probabilidade, nas quais puderam refletir sobre a sua atuação em sala de aula e as dificuldades com relação ao processo de ensino e aprendizagem. É nessa perspectiva que o projeto contribuiu para o desenvolvimento dos saberes do contexto educacional, como registrou o licenciando L9, sobrepondo seu registro L9N1, descrito anteriormente.

Essa disciplina contribuiu para que eu conheça maneiras de trabalhar a estatística em minha futura prática docente, conhecendo meios de desenvolver essas habilidades estatísticas e despertar o interesse do aluno ao realizar investigações (L9M2).

Os licenciandos compreendem a importância do ensino de Estatística em sala de aula para e a sua aplicabilidade "o aluno deve ter acesso aos conteúdos de Estatística para que saiba utilizá-los em sua vivência na sociedade, L1N2”. Entendem os conteúdos que devem ser ensinados aos alunos e quando isso deve acontecer "no Ensino Médio poderia trabalhar com desvio padrão e variância, na intenção de diversificar as aulas com algo de interesse dos alunos, L4N6”.

Conforme o registro L1N2 esses aspectos devem ser considerados na perspectiva nos quais os alunos tenham um papel ativo na sua aprendizagem "o aluno deve perceber que ele é o próprio construtor do seu conhecimento e o professor um auxiliar, L1N2" e ao professor cabe responder os questionamentos e orientar nas descobertas para novas aprendizagens. 
O desenvolvimento da capacidade crítica de compreensão estatística dos alunos é facilitado pela orientação dos professores e, para isso, é necessário que estes, em sala de aula, tenham plena consciência da importância, em particular, dos conteúdos de Estatística nessa formação crítica do aluno e de sua capacidade de lidar com incertezas e aproximações. Além disso, é fundamental que o professor tenha um repertório de saberes docentes disciplinares, pedagógicos da disciplina e curriculares para trabalhar os principais conceitos ligados à Probabilidade e à Estatística (Costa, 2007 p. 138).

Portanto, percebe-se nos excertos pertencentes a essa unidade de análise, que os licenciandos compreendem o contexto da sala de aula e entendem que a aprendizagem dos alunos está relacionada com a sua prática pedagógica. Esses saberes foram manifestados e/ou desenvolvidos principalmente com as discussões referentes às tarefas e sua articulação com a Educação Básica.

\section{Considerações Finais}

Conforme apresentado nas discussões dos resultados, os licenciandos desenvolveram e/ou manifestaram os saberes da docência ao longo do projeto de forma articulada e que aparecem nas subcategorias e unidades de análise. Isso nos permitiu interpretar que os saberes não são independentes e que se desenvolvem em conjunto. As tarefas, as leituras e discussões dos textos, a investigação estatística e a elaboração da atividade, estavam todos em consonância, na perspectiva da formação profissional e do desenvolvimento dos saberes docentes que puderam ser manifestados pelas narrativas de aprendizagem e pelos memoriais reflexivos.

Por entender que existem falhas na a) formação inicial do professor de Matemática para o ensino de Estatística e Probabilidade para a Educação Básica e a necessidade de uma disciplina específica ${ }^{4}$ que trate esse tema, é que foi elaborado um Projeto de Ensino de Estatística com atividades teóricas e específicas, que poderão auxiliar o professor do Ensino Superior em uma disciplina que envolva a Estatística e Probabilidade.

Ao considerar b) as práticas que os licenciandos irão participar como forma de contribuir para a melhoria do processo educacional ofertou-se uma formação voltada para o ensino e aprendizagem de Estatística e Probabilidade, por meio da realização de tarefas, leitura e discussão de textos científicos, participação em uma investigação estatística e elaboração de uma atividade de ensino.

Entende-se que c) as ações específicas de um professor formador em sala de aula interferem de forma significativa no perfil dos licenciandos, que de certo modo irão reproduzir

\footnotetext{
${ }^{4}$ Essa discussão pode ser encontrada em Damin (2018).
} 
esses saberes da na Educação Básica (como no caso do desenvolvimento de uma investigação estatística). Espera-se que em um curso de Licenciatura em Matemática não sejam priorizadas disciplinas específicas de conteúdo em detrimento das outras de cunho pedagógico, pois, poderá induzir os licenciandos a supervalorizarem o conteúdo específico e que sejam superficiais em aspectos didáticos e pedagógicos. Portanto, ao elaborar e desenvolver o projeto desejou-se um equilíbrio de perspectivas, oportunizando ao licenciando construir um repertório de saberes para o ensino de Estatística e Probabilidade.

As diretrizes curriculares nacionais discutem a importância da aproximação e articulação entre Ensino Superior e Educação Básica, desta forma, com a finalidade de se ofertar uma formação de mais qualidade ao futuro professor, destaca-se assim, d) a contribuição dos currículos do Ensino Superior e da Educação Básica para prática docente, pois são esses documentos oficiais que norteiam o sistema educacional brasileiro. Esse aspecto apareceu quando articulou-se as competências e habilidades que devem ser ofertadas pela licenciatura com o currículo da Educação Básica. Dessa forma, os saberes da docência foram manifestados, pois os licenciandos, criaram, planejaram, realizaram, geriram e avaliaram situações didáticas em conformidade com as diretrizes.

\section{Referências}

Albuquerque, L. C., \& Gontijo, C. H. (2013). A complexidade da formação do professor de matemática e suas implicações para a prática docente. Espaço Pedagógico, v. 20, n. 1, p. 76-87, jan./jun. Recuperado de http://www.upf.br/seer/index.php/rep/article/view/3508/2293

Almeida, P. C. A., \& Biajone, J. (2007). Saberes docentes e formação inicial de professores: implicações e desafios para as propostas de formação. Educação e Pesquisa, v. 33, n. 2, p. 281-295, mai/ago. Recuperado de http://www.scielo.br/pdf/ep/v33n2/a07v33n2.pdf

American Statistical Association. (2005). Guidelines for Assessment and Instruction in Statistics Education (GAISE) Report: A Pre-K-12 Curriculum Framework. Alexandria, 2005. Recuperado de http://www.amstat.org/education/gaise/GAISEPreK12_Intro.pdf

Azcárate G. P., Cardeñoso, J. M., \& Pórlan, R. (1998). Concepciones de futuros professores de primaria sobre la noción de aleatoriedade. Enseñanza de las Ciências, Barcelona, v. 16, n. 1, p. 85-9.

Borges, C. M. F., \& Tardif, M. (2001). Apresentação. In: Educação \& Sociedade - Dossiê: Os saberes dos docentes e sua formação. Campinas (SP), v. 22, n. 74, p. 11-26.

Brasil. Ministério da Educação (2001). Conselho Nacional de Educação. Parecer n ${ }^{\circ}$ 9, de 08 de maio de 2001. Diretrizes Curriculares Nacionais para a Formação de Professores da 
Educação Básica, em nível superior, curso de licenciatura, de graduação plena. Brasília, DF, p. 1-70, 2001. Recuperado de http://portal.mec.gov.br/cne/arquivos/pdf/009.pdf

Brasil. (2015). Ministério da Educação. Conselho Nacional de Educação. Resolução no 2, de 01 de julho de 2015. Diretrizes Curriculares Nacionais para a Formação Inicial e Continuada em Nivel Superior de Profissionais do Magistério para a Educação Básica. Brasília, DF, p. 1-78.

Burgess, T. A. (2007). Investigating the nature of teacher knowledge needed and used in teaching statistics. Thesis (Doctorate in Education) - Massey University, Palmerston North, Nova Zelândia. Recuperado de https://iaseweb.org/documents/dissertations/07.Burgess.Dissertation.pdf

Campos, C. R. (2007). A Educação estatística: uma investigação acerca dos aspectos relevantes à didática da estatística em cursos de graduação. Tese (Doutorado em Educação) Universidade Estadual Paulista, Rio Claro (SP), 2007.

Campos, C. R, et al. (2011). Educação Estatística no Contexto da Educação Crítica. Bolema, Rio Claro (SP), v. 24, n. 39, p. 473-494, ago.

Campos, C. R., Wodewotzki, M. L. L., Jacobini, O. (2011). Educação estatística: teoria e prática em ambientes de modelagem matemática. Belo Horizonte: Autêntica.

Cavalcante, J. L., Andrade, V. L. V. X., \& Régnier, J. (2016). O conceito de probabilidade na formação docente: uma reflexão apoaida pela análise estatística implicativa. VIDYA, Santa Maria (RS), v. 36, n. 2, p. 441-455, jul./dez.

Cazorla, I. M. (2002). A relação entre a habilidade viso-pictórica e o domínio de conceitos estatísticos na leitura de gráficos. Tese (Doutorado em Educação) - Faculdade de Educação, Universidade Estadual de Campinas. Campinas.

Costa, A. (2007). A Educação Estatística na formação do professor de Matemática. Dissertação (Mestrado em Educação) - Programa de Pós-Graduação em Educação, Universidade São Francisco. Itatiba.

Costa, A., Nacarato, A. M. (2011). A Estocástica na Formação do Professor de Matemática: percepções de professores e de formadores. Bolema, Rio Claro (SP), v. 24, n. 39, p. 367386.

Cyrino, M. C. C. T. (2007). Preparação e emancipação profissional na formação inicial do professor de Matemática. In: A. M. Nacarato, \& M. A. V. Paiva. (Eds). A formação do professor que ensina Matemática: pesquisas e perspectivas. (pp. 77-88).

Damin, W. (2018). A educação estatística e a formação de professores de matemática: contribuições de um projeto para a constituição dos saberes docentes. Tese (Doutorado em Ensino de Ciência e Tecnologia) - Programa de Pós-Graduação em Ensino de Ciência e Tecnologia, Universidade Tecnológica Federal do Paraná. Ponta Grossa.

Lopes, C. A. (2003). O conhecimento profissional dos professores e suas relações com estatística e probabilidade na educação infantil. Tese (Doutorado em Educação). 
Faculdade de Educação, Universidade Estadual de Campinas. Campinas (SP).

Lopes, C. A. (2008). O Ensino da Estatística e da Probabilidade na Educação Básica e a Formação dos Professores. Cad. Cedes, Campinas, vol. 28, n. 74, p. 57-73, jan./abr. Recuperado de http://www.cedes.unicamp.br

Lopes, C. A. (2013). Educação Estatística no Curso de Licenciatura em Matemática. Bolema, Rio Claro (SP), v. 27, n. 47, p. 901-915, dez.

Pamplona, A. S., Carvalho, D. L. (2009). O Ensino de Estatística na Licenciatura em Matemática: a inserção do licenciando na comunidade de prática dos professores de Matemática. Bolema, Rio Claro (SP), Ano 22, nº 32, 2009, p. 47-60.

Sulman, L. (1986). Those who understand: knowledge growth in teaching. Educational Researcher, Washington (EUA), v. 15, n. 2, p. 4-14.

Tardif, M. (2014). Saberes docentes e formação profissional. 17. ed. Petrópolis, RJ: Vozes.

Submetido em: 30/03/2019

Aceito em: 07/09/2019 